\title{
A Comparison Of Irish Surnames In The United States With Those Of Eire
}

\author{
D Kenneth Tucker \\ Carleton University, Ottawa
}

This paper compares contemporary frequency distributions of Irish Surnames in Eire (2001) and the United States (US) (1997), about one hundred years after bulk of Irish emigration to the US, in order to measure changes, if any, in form and frequency of these surnames.

The Eire Data (ED) source is taken from the Eire 2002 Electoral Roll, where the graph of population against surnames is shown to be typical. The US Data (USD) source is Hanks' Dictionary of American Family Names (DAFN). Results of a first comparison of these two sources prompted removal from the USD of all Irish surnames that also have UK roots, including 33 of the 100 most frequent surnames in the Eire data. A second comparison shows that many US surnames of Irish origin are not present in Eire: these are variants of common Irish surnames, and were then merged with the etymological Irish form. The remaining 67 of the most frequent 100 surnames from ED were then compared with USD. All except one are of roughly comparable frequency order albeit with some changes to their spelling form. It is concluded that the US Irish surnames clearly reflect their heritage although some are have never been found in Eire.

This study was conducted to see if the current surnames of Eire and of USA are related by frequency and to demonstrate the changes in spelling that occurred, principally in USA.

What is an Irish surname? An Irish surname can be defined for the purpose here as a surname that originated in Eire but which may have undergone a change in format, including spelling, in the US. In this study I have used Hanks and MacLysaght as my principal guides as to what is an Irish surname.

The 2002 Eire Census shows that over a quarter of a million nationals from all continents reside in Eire; it is becoming, if not already, a pluralistic society: see Table 1 . We could expect that many of, but not all, the Irish nationals to have Irish surnames, and conversely, that there may be other

Names 54:1 (March 2006):55-75

ISSN:0027-7738

Copyright 2006 by The American Name Society 


\section{6 - NAMES 54:1 (March 2006)}

nationals resident in Eire, say from the European Union or USA, with Irish surnames. Parenthetically, the breakdown of the nationality of the residents is extremely useful for names scholars as it allows expectations to be set when considering the list of surnames.

Table 1. Eire: Population by Nationality

\begin{tabular}{|l|l|l|}
\hline NATIONALITY & POPULATION & PRINCIPALLY \\
\hline Irish & $3,584,975$ & NA \\
\hline European Union & 133,436 & UK \\
\hline Rest of Europe & 23,105 & Romania \\
\hline Africa & 20,981 & Nigeria \\
\hline Asia & 21,779 & China \\
\hline America & 15,383 & USA \\
\hline Australasia & 3,706 & Australia \\
\hline Not Stated & 48,412 & NA \\
\hline None & 847 & NA \\
\hline
\end{tabular}

\section{The Eire Data (ED)}

The Eire source is the Electoral Roll for Eire as collected by the authorities in Eire in 2001, and consolidated by Experian UK. The surnames from the Electoral Roll were made available to me in 2004, by Experian, through the good offices of Professor Richard Webber, of University College London (UCL), whom I wish to thank for his continuing support. The ED represents almost three million people with 55,298 different surname types, where each type represents a different spelling.

The 2002 Census in Eire as recorded by the Eire Central Statistics Office (www.cso.ie gives the population of Eire as $3,917,203$ of which 1,946,164 were males and 1,971,039 were females. This ratio of males to females of 1 male to 1.01 females is low compared with the US. What is more unusual is that females only outnumber males in two of the eight age groups: $25-44$ and 65 and over. 
Using the Census data we can estimate the likely size of the Electoral Roll and compare the estimate with the size of the Electoral Roll data from Experian. The Electoral Roll would include data on those of 17 years and over, the putative voters. Eire, as a member of the EU enfranchises those of 18 years and older. Since the Electoral Roll is created prior to an election the collection range is 17 years and above.

From the data available this would be a total of about 3 million people. It is not possible to be more accurate since the first two age groups are $0-14(827,428)$, and $15-19(313,188)$ and straddle the age of 17 . However, this estimate compares well with the 2,917,186 records in the Electoral Roll, albeit that such rolls usually have duplicate records. Table 2 lists the top 100 surnames from the ED by frequency, or count.

Table 2. The Top 100 Surnames in the Eire Electoral Roll 2001

\begin{tabular}{|l|l|l|}
\hline RANK & SURNAME & COUNT \\
\hline 1 & Murphy & 49585 \\
\hline 2 & Kelly & 38736 \\
\hline 3 & Byrne & 31405 \\
\hline 4 & Walsh & 31316 \\
\hline 5 & O'Brien & 30917 \\
\hline 6 & Ryan & 30892 \\
\hline 7 & O'Connor & 27514 \\
\hline 8 & O'Sullivan & 24671 \\
\hline 9 & Doyle & 20745 \\
\hline 10 & McCarthy & 18744 \\
\hline 11 & O'Neill & 18056 \\
\hline 12 & Lynch & 16451 \\
\hline 13 & Dunne & 14273 \\
\hline 14 & Murray & 13809 \\
\hline 15 & Brennan & 13714 \\
\hline 16 & Burke & 13371 \\
\hline 17 & Daly & 13169 \\
\hline 18 & Smith & 13112 \\
\hline 19 & Nolan & 12628 \\
\hline 20 & O'Reilly & 12371 \\
\hline 21 & Kennedy & 12179 \\
\hline 22 & Farrell & 11698 \\
\hline 23 & Fitzgerald & 11469 \\
\hline 24 & Carroll & 11364 \\
\hline 25 & Gallagher & 11224 \\
\hline 26 & Power & 11193 \\
\hline 27 & Flynn & 11027 \\
\hline & & \\
\hline
\end{tabular}


58 - NAMES 54:1 (March 2006)

\begin{tabular}{|c|c|c|}
\hline 28 & O'Connell & 10974 \\
\hline 29 & Collins & 10878 \\
\hline 30 & Quinn & 10846 \\
\hline 31 & Kavanagh & 10618 \\
\hline 32 & Connolly & 10321 \\
\hline 33 & Healy & 9618 \\
\hline 34 & Doherty & 9490 \\
\hline 35 & Reilly & 9474 \\
\hline 36 & McGrath & 9346 \\
\hline 37 & Whelan & 9204 \\
\hline 38 & Clarke & 9198 \\
\hline 39 & Duffy & 9112 \\
\hline 40 & O'Shea & 9064 \\
\hline 41 & O'Donnell & 9057 \\
\hline 42 & Brady & 9046 \\
\hline 43 & O'Leary & 9043 \\
\hline 44 & Keane & 9032 \\
\hline 45 & Kenny & 9007 \\
\hline 46 & Moran & 8523 \\
\hline 47 & Moore & 8507 \\
\hline 48 & Fitzpatrick & 8357 \\
\hline 49 & Barry & 8335 \\
\hline 50 & Hayes & 8134 \\
\hline 51 & Foley & 8000 \\
\hline 52 & Maher & 7887 \\
\hline 53 & Casey & 7867 \\
\hline 54 & Martin & 7748 \\
\hline 55 & Roche & 7680 \\
\hline 56 & McMahon & 7676 \\
\hline 57 & Buckley & 7516 \\
\hline 58 & O'Keeffe & 7321 \\
\hline 59 & Ward & 7090 \\
\hline 60 & McDonnell & 6926 \\
\hline 61 & O'Mahony & 6887 \\
\hline 62 & Hogan & 6877 \\
\hline 63 & Browne & 6855 \\
\hline 64 & Hughes & 6809 \\
\hline 65 & Griffin & 6800 \\
\hline 66 & O'Callaghan & 6728 \\
\hline 67 & McCormack & 6657 \\
\hline 68 & Cullen & 6596 \\
\hline 69 & White & 6574 \\
\hline 70 & Sweeney & 6541 \\
\hline 71 & O'Donovan & 6487 \\
\hline 72 & Delaney & 6391 \\
\hline 73 & Butler & 6346 \\
\hline 74 & Maguire & 6319 \\
\hline 75 & Hickey & 6296 \\
\hline 76 & McLoughlin & 6295 \\
\hline 77 & Egan & 6230 \\
\hline 78 & Sheehan & 6226 \\
\hline 79 & Cronin & 6163 \\
\hline
\end{tabular}




\begin{tabular}{|l|l|l|}
\hline 80 & McNamara & 6128 \\
\hline 81 & O'Donoghue & 6055 \\
\hline 82 & Cunningham & 5956 \\
\hline 83 & Lyons & 5915 \\
\hline 84 & McDonagh & 5821 \\
\hline 85 & Keogh & 5821 \\
\hline 86 & Higgins & 5694 \\
\hline 87 & Sullivan & 5646 \\
\hline 88 & McKenna & 5520 \\
\hline 89 & Barrett & 5504 \\
\hline 90 & Curran & 5480 \\
\hline 91 & Smyth & 5474 \\
\hline 92 & Cahill & 5450 \\
\hline 93 & O'Rourke & 5438 \\
\hline 94 & Moloney & 5355 \\
\hline 95 & Crowley & 5352 \\
\hline 96 & Flanagan & 5286 \\
\hline 97 & Mooney & 5278 \\
\hline 98 & Sheridan & 5271 \\
\hline 99 & Molloy & 5211 \\
\hline 100 & Corcoran & 5181 \\
\hline & & \\
\hline
\end{tabular}

Graph 1 shows the plot of cumulative population against number of surname types for ED. This curve is typical for surname distributions in USA 1997 (Tucker 2001; Hanks 2003), Canada 1997 (Tucker 2002), UK 1881 (Tucker 2005), and UK 1997 (Tucker 2004); it differs only in degree. For example consider the $1 \%$ of the surname types level. At this level the UK 1881 graph reaches almost $75 \%$ population level, and the1997 graph reaches $80 \%$; the US 1997 graph reaches almost $73 \%$, whereas the ED graph reaches this level at $69 \%$ showing a society where the most popular surnames are not as dominant as in the UK, or even as in the US. However, in Canada the level is only a little over $63 \%$ of the population for $1 \%$ of the surname types. 


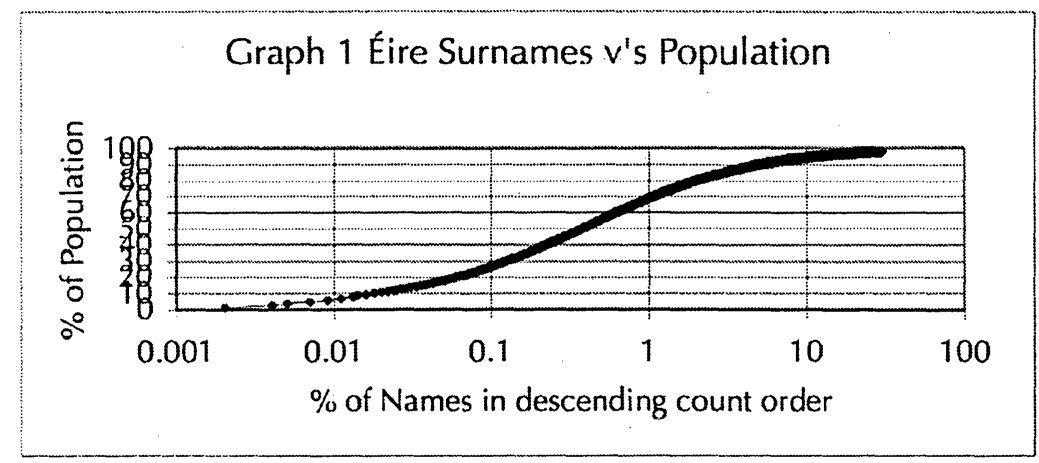

Graph 2 shows the count for individual surnames plotted against rank. This curve is, and should be, monotonically descending since that is the way the data are ordered, but that with logarithmic scales for both count and rank, as it has, the curve for a purely power law relationship would be a straight line of the form $K^{*} x^{* *} p$ where $K$ is the count of the Number One ranked surname, and $p$ is negative. This expression should be read as: $y$ equals $K$ multiplied by $x$ raised to the power $\mathrm{p}$.

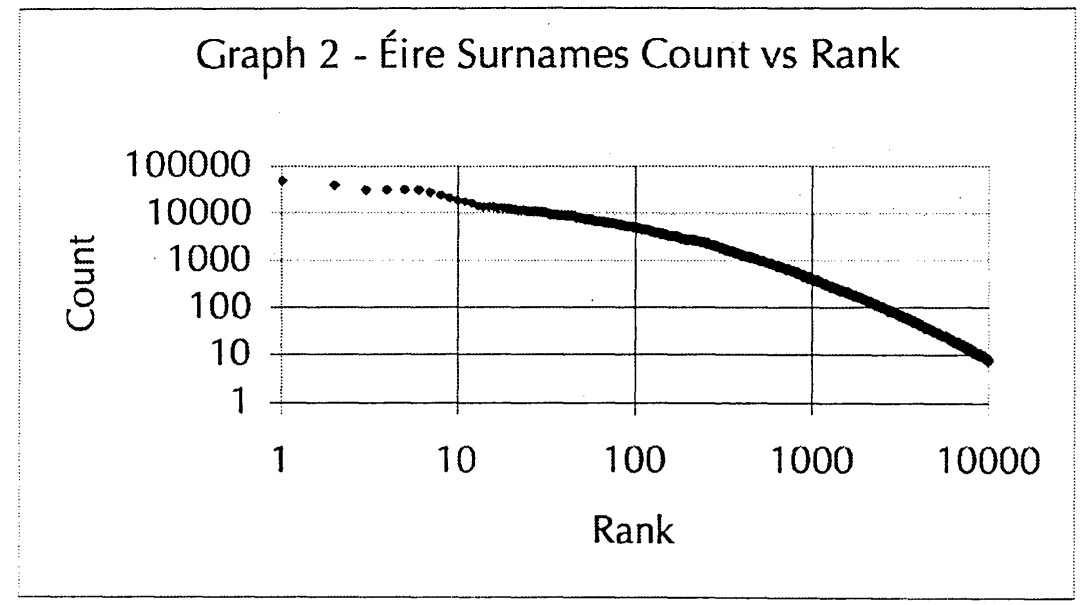

Clearly the plot is not a straight line. It is not a simple power-law relationship, although approximate power law relationships hold for various rank sectors as shown in the table below. It is more complicated than a simple power law as 
others have demonstrated for other applications and it has been the subject of much discussion and approximation has can be seen by any web search of Zipf's Law. Eg http:/ / en.wikipedia.org.

The Coefficients for the three Power Law sectors of ED

\begin{tabular}{|l|l|l|}
\hline Rank & $\mathrm{K}$ & $\mathrm{p}$ \\
\hline $1-9$ & 49264 & -0.33 \\
\hline $10-249$ & 84835 & -0.63 \\
\hline $250-10,000$ & 20782673 & -1.59 \\
\hline
\end{tabular}

The graph should be, according to Zipf's Law, a straight line - a pure power law relationship; clearly it is not. The curve drops away continuously to become convex as seen from above. However, identical curves have been shown for the US surnames (Tucker 2001), contemporary UK surnames (Tucker 2004a), UK surnames from the 1881 Census, contemporary Canadian and Australian surnames, (DKT Paper at ANS Jan 05). Zipf's Law may be a useful approximation but the ED is typical of surname data.

Interestingly, many of the low count surnames are not real surnames but typographical errors of surnames that appear earlier in rank. For example Smiyh, with a count of 1, and rank of 33,009, is an adjacent letter substitution typographical error for Smith which has count of 13,112 and rank of 18. If the typographical error had not been made, Smith would have had a count 13,113 and the same rank, in this case. However, there would have been no entry for Smiyh. The impact of removing the typographical error would be to:

1. Reduce the apparent number of types, and thus the length of the $x$ axis.

2. Increase the count of non-typographical error types

3. In some cases to increase the rank of some types 
All three effects make the true curve more convex than shown. It would be, because of the logarithmic scales, more noticeable at the low counts and high scoring ranks: the real curve would drop off more sharply at the end. Thus typographical errors tend to mask, somewhat, the non-power law relationship between surnames and their counts. This argument applies to all surnames sets gathered in a similar fashion.

I have proven that the UK Electoral Roll, a similar file of 47 million surnames of over 781 thousand types, has a typographical error rate in excess of $2 \%$ in types. I estimate that the actual rate is in excess of 5\% (Tucker 2004b). Some egregious errors in ED are: O['connor, O;neill, Kenn $\backslash$, 0'keeffe, and Hoarty\%, all of which could have been caught by simple hygiene tests.

\section{The US Data (USD)}

The US source is the 2003 edition of DAFN, a reference work which, in addition to giving etymologies and occasional family histories, includes frequency counts in the source data for comparative purposes. DAFN has over 70,000 surnames, about $4 \%$ of US surname types, and which represents the top $85 \%$ of the population.

Since Hanks has included counts in DAFN as well as etymologies it is a source of contemporary data for particular surname sources. For example the extraction of Irish surnames is no different in principal than the extraction of Scandinavian surnames. From DAFN I extracted all 5,060 surnames that have an Irish root. The top 100 putative Irish surnames with their frequencies are listed in Table 3 . The count for the USD is almost 18 million. Care should be taken with this number, as the DAFN source is the telephone directories; a rough guide would be about 2.5 people per telephone line, so the population covered by USD would be about 45 million people.

Table 3 The Top 100 Surnames in DAFN with Irish Roots 
Irish Surnames $\bullet 63$

\begin{tabular}{|c|c|c|c|c|c|}
\hline RANK & SURNAME & COUNT & RANK & SURNAME & COUNT \\
\hline 1 & Brown & 447208 & 51 & Tucker & 56636 \\
\hline 2 & Anderson & 285232 & 52 & Ryan & 56499 \\
\hline 3 & Wilson & 269682 & 53 & Shaw & 56401 \\
\hline 4 & Moore & 239230 & 54 & Owens & 56055 \\
\hline 5 & Martin & 238747 & 55 & Freeman & 55281 \\
\hline 6 & White & 217049 & 56 & Crawford & 55113 \\
\hline 7 & Jackson & 184136 & 57 & Palmer & 54798 \\
\hline 8 & Lee & 180338 & 58 & Hunt & 54737 \\
\hline 9 & Lewis & 166842 & 59 & Henry & 53692 \\
\hline 10 & Hall & 166370 & 60 & Black & 53244 \\
\hline 11 & Young & 160864 & 61 & Woods & 52881 \\
\hline 12 & Wright & 148099 & 62 & Mills & 52726 \\
\hline 13 & Scott & 137971 & 63 & Kelley & 52553 \\
\hline 14 & Green & 131873 & 64 & Warren & 52256 \\
\hline 15 & Mitchell & 122922 & 65 & Dunn & 51549 \\
\hline 16 & Carter & 116042 & 66 & Hunter & 51238 \\
\hline 17 & Murphy & 115601 & 67 & Peters & 51189 \\
\hline 18 & Morris & 110158 & 68 & Hart & 50153 \\
\hline 19 & Cook & 109743 & 69 & Pierce & 49516 \\
\hline 20 & Collins & 107617 & 70 & Carroll & 49397 \\
\hline 21 & Morgan & 97713 & 71 & O'Brien & 49025 \\
\hline 22 & Kelly & 94726 & 72 & Holmes & 48841 \\
\hline 23 & Cox & 94703 & 73 & Hanson & 47293 \\
\hline 24 & Ward & 92242 & 74 & Lane & 47026 \\
\hline 25 & Sullivan & 86937 & 75 & Burke & 47014 \\
\hline 26 & Myers & 84848 & 76 & Cunningham & 46903 \\
\hline 27 & Hughes & 84186 & 77 & Armstrong & 46612 \\
\hline 28 & Howard & 84046 & 78 & Duncan & 46466 \\
\hline 29 & Long & 83277 & 79 & Berry & 46082 \\
\hline 30 & Russell & 79186 & 80 & Cohen & 46018 \\
\hline 31 & Fisher & 78653 & 81 & Knight & 45435 \\
\hline 32 & Powell & 74080 & 82 & Bradley & 45011 \\
\hline 33 & Butler & 70457 & 83 & Hawkins & 44465 \\
\hline 34 & Barnes & 70136 & 84 & Greene & 44408 \\
\hline 35 & Henderson & 69047 & 85 & Riley & 44266 \\
\hline 36 & Hamilton & 68294 & 86 & Lynch & 44057 \\
\hline 37 & Patterson & 67787 & 87 & Matthews & 43160 \\
\hline 38 & Cole & 66813 & 88 & Walsh & 43045 \\
\hline 39 & Murray & 66484 & 89 & Carr & 41809 \\
\hline 40 & Wallace & 66195 & 90 & Harper & 41293 \\
\hline 41 & Meyer & 65510 & 91 & Williamson & 40959 \\
\hline 42 & Hayes & 64858 & 92 & Montgomery & 39082 \\
\hline 43 & Kennedy & 64834 & 93 & Dean & 39048 \\
\hline 44 & Griffin & 64218 & 94 & Keller & 38840 \\
\hline 45 & Coleman & 63715 & 95 & Day & 38582 \\
\hline 46 & Alexander & 63462 & 96 & May & 38472 \\
\hline 47 & Burns & 60369 & 97 & Harvey & 38284 \\
\hline 48 & Ford & 59533 & 98 & Holland & 36823 \\
\hline 49 & Fox & 58103 & 99 & Little & 35412 \\
\hline 50 & Gordon & 57047 & 100 & McCoy & 34738 \\
\hline
\end{tabular}




\section{The First Comparison of ED with USD}

Simply mapping ED onto USD gave some very peculiar results as shown in Table 4 . The most frequent ED surname, Murphy is the $17^{\text {th }}$ entry in USD. An Irish origin would not readily spring to mind for the top 16 surnames in USD: Brown, Anderson, Wilson, et al. Brown, the most frequent name in the USD with an Irish root, is not particularly frequent in Eire at rank 219 in ED. The mismatch arises because Brown, in the US, also has other origins. Etymologically, according to DAFN, it has English, Scottish, and Irish roots, but that "it has absorbed numerous surnames from other languages with the same meaning". All the top 16 USD surnames have roots in addition to Irish, sometimes the non-Irish roots are more common. Murphy is the most frequent USD surname that has an exclusively Irish origin.

Table 4. The First Comparison of ED with the first 25 of USD

\begin{tabular}{|l|l|r|}
\hline ED RANK & SURNAME & $\begin{array}{l}\text { USD } \\
\text { RANK }\end{array}$ \\
\hline 219 & Brown & 1 \\
\hline 365 & Anderson & 2 \\
\hline 223 & Wilson & 3 \\
\hline 47 & Moore & 4 \\
\hline 54 & Martin & 5 \\
\hline 69 & White & 6 \\
\hline 338 & Jackson & 7 \\
\hline 137 & Lee & 8 \\
\hline 551 & Lewis & 9 \\
\hline 361 & Hall & 10 \\
\hline 300 & Young & 11 \\
\hline 400 & Wright & 12 \\
\hline 328 & Scott & 13 \\
\hline 503 & Green & 14 \\
\hline 220 & Mitchell & 15 \\
\hline 450 & Carter & 16 \\
\hline 1 & Murphy & 17 \\
\hline 186 & Morris & 18 \\
\hline 2403 & Cook & 19 \\
\hline 29 & Collins & 20 \\
\hline 217 & Morgan & 21 \\
\hline 2 & Kelly & 22 \\
\hline 301 & Cox & 23 \\
\hline 59 & Ward & 24 \\
\hline 87 & Sullivan & 25 \\
\hline & & \\
\hline
\end{tabular}


To make the comparison more meaningful, all surnames with Irish roots but with one or more UK roots: English, Scottish, Welsh, or Northern Irish, were excluded from the USD. Northern Irish were able to be excluded as DAFN differentiates between Irish and Northern Irish roots. The USD data set was thus reduced to 2,826 surnames of putatively Irish origin, with a count of almost four million. USA.

\section{The Second Comparison of ED with USD}

Strictly speaking, the comparison is USD with ED, where the 2,826 records of the USD are mapped onto the ED. There is more overlap than previously; seven of the top ten in the ED appear in the top 10 of the USD, as can be seen in Table 5 which lists the top 25 Irish Surnames by ED rank for which there is an entry in USD.

Table 5. The Second Comparison: USD compared to ED

\begin{tabular}{|l|l|r|}
\hline ED & SURNAME & USD \\
RANK & & 1 \\
\hline 1 & Murphy & 2 \\
\hline 2 & Kelly & 55 \\
\hline 3 & Byrne & 7 \\
\hline 4 & Walsh & 6 \\
\hline 5 & O'Brien & 4 \\
\hline 6 & Ryan & 10 \\
\hline 7 & O'Connor & 173 \\
\hline 8 & O'Sullivan & 14 \\
\hline 9 & Doyle & 9 \\
\hline 10 & McCarthy & 25 \\
\hline 11 & O'Neill & 218 \\
\hline 13 & Dunne & 24 \\
\hline 15 & Brennan & 48 \\
\hline 17 & Daly & 30 \\
\hline 19 & Nolan & 163 \\
\hline 20 & O'Reilly & 21 \\
\hline 22 & Farrell & 13 \\
\hline 23 & Fitzgerald & 5 \\
\hline 24 & Carroll & 15 \\
\hline 25 & Gallagher & 17 \\
\hline 27 & Flynn & 38 \\
\hline 28 & O'Connell & 12 \\
\hline 30 & Quinn & 345 \\
\hline 31 & Kavanagh & 56 \\
\hline 32 & Connolly & \\
\hline
\end{tabular}


Some high ED Ranks are missing from the list in Table 5, such as: 12 Lynch, 14 Murray, 16 Burke, 18 Smith, 21 Kennedy, 26 Power, \& 29 Collins,. This is because these surnames were eliminated from USD as part of the Irish only selection explained above. Not only are there surnames in ED missing from USD, there are surnames in USD that do not appear in ED. Over a third of the surnames in USD, $(1,018$ of 2,826$)$ do not appear amongst the 55,286 types in ED. If these names are indeed of Irish origin, they have either become extinct in Eire, or they have changed their form, become variants, from the spelling used in Eire.

\section{The Variants}

The 1,018 USD types not found in ED were investigated further; they were over-whelmingly, 837, variants of more common Irish surnames, or in some cases an Anglicization of a Gaelic form. The top 25 variants are listed in Table 6 together with the surname that they are a variant of; for example: Daugherty, 12,706 is Rank 50 in USD but does not appear in ED. According to DAFN, it is a variant of Doherty, a surname that appears prominently in ED.

Table 6 The Top 25 Variants in USD not in ED

\begin{tabular}{|r|l|r|l|}
\hline RANK & VARIANT & COUNT & VARIANT OF \\
\hline 50 & Daugherty & 12706 & Doherty \\
\hline 65 & Ferrell & 11277 & Farrell \\
\hline 68 & Dailey & 11185 & Daly \\
\hline 76 & Talley & 9801 & Tulley \\
\hline 78 & Whalen & 9553 & Whelan \\
\hline 91 & Conklin & 8733 & Coughlin \\
\hline 115 & Cavanaugh & 6930 & Kavanagh \\
\hline 124 & Goins & 6594 & Going \\
\hline 144 & Mahan & 5611 & Mohan \\
\hline 154 & McClendon & 4956 & McClinton \\
\hline 156 & Roark & 4887 & O'Rourke \\
\hline 174 & Gann & 4513 & McGann \\
\hline 191 & Boyles & 4191 & Boyle \\
\hline 196 & Ragan & 4102 & Regan \\
\hline 209 & Doan & 3711 & Doane \\
\hline 211 & Nolen & 3672 & Nolan \\
\hline 219 & Shay & 3572 & Shea \\
\hline 224 & McGrew & 3400 & Mulgrew \\
\hline
\end{tabular}


Irish Surnames $\bullet 67$

\begin{tabular}{|l|l|r|l|}
\hline 254 & Harbin & 2868 & Herbert \\
\hline 259 & Donley & 2785 & Donnelly \\
\hline 275 & Haynie & 2573 & Heaney \\
\hline 279 & Runyan & 2529 & Runyon \\
\hline 280 & Hughey & 2506 & Huey \\
\hline 281 & Gaddy & 2498 & Geddie \\
\hline 282 & McGehee & 2494 & McGahey \\
\hline
\end{tabular}

In 161 cases the surname was seen to have more than an Irish root, other than a UK root. An example of the later would be Meyer, 65,510 which has German, Dutch, Jewish, and Danish roots in addition to Irish roots. These 161 surnames with roots in addition to Irish were deleted from USD as they distort the comparison of USD with ED. For the remaining 20 surnames there was no etymological explanation; these surnames generally had low counts, and were also deleted.

The counts for surnames in USD that were variants (eg Flaharty, 224 a variant of Flaherty) were added to the count of the Variant of surname, and USD ordered on the amended counts. USD now comprises 1,833 records, down from the start of over 5,000 . The count for USD is now just over 3.6 million: less than a $10 \%$ reduction from the previous level. Table 7 shows examples of the USD variants not found in ED, but where the variant of is in ED, for Donahue, Donegan, Donnelly, and Donovan.

Table 7 The Variants of Donahue, Donegan, Donnelly \& Donovan in USD

\begin{tabular}{|l|r|l|}
\hline SURNAME & COUNT & VARIANT OF \\
\hline Donoho & 847 & Donahue \\
\hline Donahoo & 602 & Donahue \\
\hline Donohoo & 292 & Donahue \\
\hline Donaho & 238 & Donahue \\
\hline Donahey & 228 & Donahue \\
\hline Dunahoo & 196 & Donahue \\
\hline Donehoo & 160 & Donahue \\
\hline Danehy & 157 & Donahue \\
\hline Donohew & 109 & Donahue \\
\hline Dunagan & 1284 & Donegan \\
\hline Dunnigan & 833 & Donegan \\
\hline Dunnagan & 269 & Donegan \\
\hline Dunegan & 208 & Donegan \\
\hline
\end{tabular}




\section{8・ NAMES 54:1 (March 2006)}

\begin{tabular}{|l|r|l|}
\hline Dunagin & 117 & Donegan \\
\hline Donley & 2785 & Donnelly \\
\hline Dannelley & 155 & Donnelly \\
\hline Dannelly & 143 & Donnelly \\
\hline Donnelley & 137 & Donnelly \\
\hline Dunavant & 449 & Donovan \\
\hline Dunnavant & 388 & Donovan \\
\hline Dunivan & 324 & Donovan \\
\hline Dunavan & 180 & Donovan \\
\hline Dunevant & 147 & Donovan \\
\hline Donivan & 126 & Donovan \\
\hline Dunavin & 115 & Donovan \\
\hline
\end{tabular}

\section{The Final Comparison}

Table 8 lists the top 100 surnames in ED compared to USD. 36 of these are not present $(N P)$ as discussed earlier; the first five of these are: 12 Lynch, 14 Murray, 16 Burke, 18 Smith, and 21 Kennedy.

Table 8 The Final Comparison: USD against ED

\begin{tabular}{|l|l|l|l|}
\hline ED RANK & SURNAME & USD RANK & $\begin{array}{l}\text { SIGNIF } \\
\text { ICANT }\end{array}$ \\
\hline 1 & Murphy & 1 & F \\
\hline 2 & Kelly & 2 & F \\
\hline 3 & Byrne & 63 & T \\
\hline 4 & Walsh & 7 & F \\
\hline 5 & O'Brien & 5 & F \\
\hline 6 & Ryan & 4 & F \\
\hline 7 & O'Connor & 11 & F \\
\hline 8 & O'Sullivan & 175 & T \\
\hline 9 & Doyle & 13 & F \\
\hline 10 & McCarthy & 9 & F \\
\hline 11 & O'Neill & 29 & F \\
\hline 12 & Lynch & NP & \\
\hline 13 & Dunne & 215 & T \\
\hline 14 & Murray & NP & \\
\hline 15 & Brennan & 26 & F \\
\hline 16 & Burke & NP & \\
\hline 17 & Daly & 20 & F \\
\hline 18 & Smith & NP & \\
\hline 19 & Nolan & 22 & F \\
\hline 20 & O'Reilly & 163 & T \\
\hline 21 & Kennedy & NP & \\
\hline 22 & Farrell & 10 & F \\
\hline 23 & Fitzgerald & 15 & F \\
\hline 24 & Carroll & 6 & F \\
\hline 25 & Gallagher & 16 & F \\
\hline
\end{tabular}


Irish Surnames $\bullet 69$

\begin{tabular}{|c|c|c|c|}
\hline 26 & Power & $\mathrm{NP}$ & \\
\hline 27 & Flynn & 18 & $\bar{F}$ \\
\hline 28 & O'Connell & 45 & $\mathrm{~F}$ \\
\hline 29 & Collins & NP & \\
\hline 30 & Quinn & 14 & $\mathrm{~F}$ \\
\hline 31 & Kavanagh & 65 & $\bar{F}$ \\
\hline 32 & Connolly & 62 & $\bar{F}$ \\
\hline 33 & Healy & 89 & $\bar{F}$ \\
\hline 34 & Doherty & 21 & $\bar{F}$ \\
\hline 35 & Reilly & 36 & $\mathrm{~F}$ \\
\hline 36 & McGrath & 38 & $\bar{F}$ \\
\hline 37 & Whelan & 50 & $\mathrm{~F}$ \\
\hline 38 & Clarke & NP & \\
\hline 39 & Duffy & NP & \\
\hline 40 & O'Shea & 196 & $\mathrm{~F}$ \\
\hline 41 & O'Donnell & .33 & $\mathrm{~F}$ \\
\hline 42 & Brady & 17 & $\mathrm{~F}$ \\
\hline 43 & O'Leary & 84 & $\bar{F}$ \\
\hline 44 & Keane & NP & \\
\hline 45 & Kenny & $\mathrm{NP}$ & \\
\hline 46 & Moran & NP & \\
\hline 47 & Moore & NP & \\
\hline 48 & Fitzpatrick & 46 & $\mathrm{~F}$ \\
\hline 49 & Barry & $\mathrm{NP}$ & \\
\hline 50 & Hayes & NP & \\
\hline 51 & Foley & NP & \\
\hline 52 & Maher & 83 & $\mathrm{~F}$ \\
\hline 53 & Casey & 19 & $\bar{F}$ \\
\hline 54 & Martin & $\overline{N P}$ & \\
\hline 55 & Roche & 120 & $\bar{F}$ \\
\hline 56 & McMahon & 37 & $\bar{F}$ \\
\hline 57 & Buckley & $\overline{N P}$ & \\
\hline 58 & O'Keeffe & 606 & $\mathrm{~T}$ \\
\hline 59 & Ward & NP & \\
\hline 60 & McDonnell & 115 & $\mathrm{~F}$ \\
\hline 61 & O'Mahony & 1233 & $\mathrm{~T}$ \\
\hline 62 & Hogan & 24 & $\mathrm{~F}$ \\
\hline 63 & Brozune & NP & \\
\hline 64 & Hughes & $\mathrm{NP}$ & \\
\hline 65 & Griffin & $\mathrm{NP}$ & \\
\hline 66 & \begin{tabular}{|l|} 
O'Callaghan \\
\end{tabular} & 428 & $\mathrm{~T}$ \\
\hline 67 & McCormack & $\mathrm{NP}$ & \\
\hline 68 & Cullen & $\mathrm{NP}$ & \\
\hline 69 & White & $\overline{N P}$ & \\
\hline 70 & Sweeney & 25 & $\mathrm{~F}$ \\
\hline 71 & O'Donovan & 850 & $T$ \\
\hline 72 & Delaney & $\mathrm{NP}$ & \\
\hline 73 & Butler & $\mathrm{NP}$ & \\
\hline 74 & Maguire & 119 & $\bar{F}$ \\
\hline 75 & Hickey & $\mathrm{NP}$ & \\
\hline
\end{tabular}




\begin{tabular}{|l|l|l|l|}
\hline 76 & McLoughlin & 335 & $\mathrm{~F}$ \\
\hline 77 & Egan & 76 & $\mathrm{~F}$ \\
\hline 78 & Sheehan & 70 & $\mathrm{~F}$ \\
\hline 79 & Cronin & 99 & $\mathrm{~F}$ \\
\hline 80 & McNamara & 72 & $\mathrm{~F}$ \\
\hline 81 & O'Donoghue & 658 & $\mathrm{~T}$ \\
\hline 82 & Cunningham & $\mathrm{NP}$ & \\
\hline 84 & McDonagh & 643 & $\mathrm{~T}$ \\
\hline 85 & Keogh & 412 & $\mathrm{~F}$ \\
\hline 86 & Higgins & $\mathrm{NP}$ & \\
\hline 87 & Sullivan & 3 & $\mathrm{~T}$ \\
\hline 88 & McKenna & $\mathrm{NP}$ & \\
\hline 89 & Barrett & $\mathrm{NP}$ & \\
\hline 90 & Curran & 79 & $\mathrm{~F}$ \\
\hline 91 & Smyth & $\mathrm{NP}$ & \\
\hline 92 & Cahill & 95 & $\mathrm{~F}$ \\
\hline 93 & O'Rourke & 56 & $\mathrm{~F}$ \\
\hline 94 & Moloney & 472 & $\mathrm{~T}$ \\
\hline 95 & Cravvley & $\mathrm{NP}$ & \\
\hline 96 & Flanagan & 64 & $\mathrm{~F}$ \\
\hline 97 & Mooney & 59 & $\mathrm{~F}$ \\
\hline 98 & Sheridan & 92 & $\mathrm{~F}$ \\
\hline 99 & Molloy & 239 & $\mathrm{~F}$ \\
\hline 100 & Corcoran & 107 & $\mathrm{~F}$ \\
\hline
\end{tabular}

Where there is a match between ED and USD, the ED population represents $51 \%$ of the Eire population. This sample is more than enough to make valid comparisons.

In comparing ED with USD I have compared ranks as opposed to counts. There are two reasons for this. The first is that the counts for USD are much greater than those for ED. The second reason is that the USD counts came from telephone listings so to get a like-to-like comparison the USD count needs to be increased by a factor of about 2.5 and then the whole thing has to be normalized for direct comparison. Comparison by rank is a straightforward and intuitively obvious alternative. In comparing rankings I use the symbol \# to indicate the rank number as in "\#3" for "number 3"

Table 7 shows that Murphy is the most popular Irish surname in both ED and USD; Kelly is the second most popular in both. Byrne, \#3 in ED, is only \#63 in USD. There is an entry " $\mathrm{T}$ " in the Significant column for Byrne. The " $\mathrm{T}$ " represents the logical value True, meaning that the difference between the ED and USD ranks is significant. It would be nice 
if the ranks matched, as with Murphy and Kelly, but what about Walsh, Ryan and O'Connor? These three each have ED rankings that differ from the USD rankings but they are in the same ballpark. I have arbitrarily set the Significant value to True if:

A. USD rank is five times greater than ED rank, Eg ED rank $8 O^{\prime}$ Sullivan with USD rank of 175.

Or

B. ED rank is five times greater than USD rank. Eg ED rank 87 Sullivan with USD rank of 3

Our example is fortuitous in providing a possible explanation for these entries. Would it be that many with the surname O'Sullivan left Eire and became Sullivan in the US? I am indebted to Patrick Hanks for pointing out that about the time of the great $19^{\text {th }}$ century migrations from Ireland the Irish Gaelic elements $O$ ', meaning 'grandson of/descended from' (MacLyaght), and Mac, Mc, M' , meaning 'son of' (MacLyaght) were regularly dropped in Anglicized forms of Gaelic names, only to be reintroduced in Eire later. In this scenario $O^{\prime}$ Sullivans living in Eire, dropped the $O^{\prime}$, and some emigrate to the US as Sullivan. Later the Sullivans in Eire reverted to the O'Sullivan form. I do not know whether either, both, or neither, explanations are valid in the particular case under consideration; clearly at this period there was turbulence in the use, or non-use, of the $O^{\prime}$ element. It is at least plausible to suggest that the USD Sullivans may be compared with the ED O'Sullivans.

However, O'Reilly has a significant tag with ED\#20 and USD\#163, but Reilly does not with ED\#35 and USD\#38. So Reilly has kept its relative position whereas $O^{\prime}$ Reilly has lost ground. This differs in degree from the O'Sullivan/ Sullivan case. If we combine the Reilly and O'Reilly counts we get the equivalent rankings of ED\#9, and USD\#21, which would not draw a significant tag. 
Table 8 shows 13 of the 100 surnames to have a significant tag, of which seven are of the form $O^{\prime} X x x x$. Note that Table 8 which is ordered by ED rank and only shows 100 entries. To make the following observations the complete USD table of 1833 entries, not shown, has been referenced. The five other $O^{\prime} X x x x$ forms are:

\section{$\mathrm{O}^{\prime}$ Keeffe, ED\#58}

Keefe (not Keeffe) has a significant tag and USD\#157

Here not only has the $O^{\prime}$ been dropped but the surname has been simplified.

\section{O'Mahony, ED\#61}

Mahoney (not Mahony) has a significant tag and USD\#32. Here again the $O^{\prime}$ been dropped and the surname simplified.

O'Callaghan, ED\#66

Callahan (not Callaghan) has a significant tag and USD\#26. Here again the $O^{\prime}$ been dropped and the surname simplified.

O’Donovan, ED\#71

Donovan has a significant tag and USD\#34. Here the $O^{\prime}$ been dropped.

O’Donoghue, ED\#81

Donahue (not Donoghue) has a significant tag and USD\#44. Here again the $O^{\prime}$ been dropped and the surname simplified.

None of the above pairs would rate a significant tag in their own right, which suggests that for at least these $O^{\prime} X x x x$ surnames, the $O^{\prime}$ was dropped, possibly prior, or at the time of migration to the US when often the surname was simplified. This is not to say all $O^{\prime} X x x x$ surnames followed the same pattern as O'Brien, O'Connor, O'Neill, and O'Connell demonstrate.

We are thus left in the top $100 \mathrm{ED}$ ranked surnames with Byrne, Dunne, McDonagh, and Moloney tagged with significant differences between ED and USD ranking. 


\section{Byrne ED\#3}

Byrne has two major variants: Byrn and Byrns. If the count for Byrne was supplemented by the count for this pair the USD rank would rise from 63 to 57, but not enough to avoid the significant tag. It appears that Byrne while quite popular in USD has not matched the relative popularity it enjoys in Eire. A possible explanation is that comparatively few Byrnes migrated to the US; another is that when they got there they changed their name to such as Burns, which, like Byrne, is an Anglicization of the Gaelic $O$ Broin. Burns is another of surnames removed from USD because of its multiple roots. However, if the latter explanation is at least partially true then ED Byrne may well be rank comparable with USD Byrne, Byrn, Byrns, and Burns and the significant tag not warranted.

Dunne ED\#13

Dunn is the major variant of Dunne and its USD count is over 14 times that of Dunne. Unfortunately, Dunn was deleted from USD as it also has English and Scottish roots. However, it is fair to say that were it possible to include only the count for the Irish Dunn then the significant tag would probably no longer be justified.

McDonagh, ED\#84

\section{McDonough USD\#87}

In DAFN Hanks gives McDonagh as a variant McDonough. However, McDonagh is the more common form in Eire, and $\mathrm{McDonough}$ more common in the US. It would seem that, etymologically speaking, McDonough should be regarded as a variant of McDonagh rather than vice versa; Hanks agrees with this interpretation. Equating the ED form with the USD form, McDonagh with MacDonough would not create a significant tag.

Moloney, ED\#94

Maloney, USD\#58

In DAFN Hanks gives Moloney as a variant of Maloney, and in USD Maloney is dominant: 12,480 to 1,216 , but the reverse is true in ED: Maloney 1,918, and Moloney 5,355. If we combine 
the counts of Maloney and Moloney for both ED and USD we get counts of 7,273 and 13,696 respectively which equate to ED59 and USD53 and thus the significant tag is not warranted.

The Significant Entries

Extract FromTable 8 The Final Comparison: USD against ED

\begin{tabular}{|l|l|l|l|}
\hline ED RANK & SURNAME & USD RANK & SIGNIFICANT \\
\hline 3 & Byrne & 63 & $\mathrm{~T}$ \\
\hline 8 & O'Sullivan & 175 & $\mathrm{~T}$ \\
\hline 13 & Dunne & 215 & $\mathrm{~T}$ \\
\hline 20 & O'Reilly & 163 & $\mathrm{~T}$ \\
\hline 58 & O'Keeffe & 606 & $\mathrm{~T}$ \\
\hline 66 & O'Callaghan & 428 & $\mathrm{~T}$ \\
\hline 71 & O'Donovan & 850 & $\mathrm{~T}$ \\
\hline 81 & O'Donoghue & 658 & $\mathrm{~T}$ \\
\hline 84 & McDonagh & 643 & $\mathrm{~T}$ \\
\hline 87 & Sullivan & 3 & $\mathrm{~T}$ \\
\hline 94 & Moloney & 472 & $\mathrm{~T}$ \\
\hline
\end{tabular}

Conclusion

Irish surnames in the US generally follow the popularity of Irish surnames in Eire; some surnames have dropped their $\mathrm{O}^{\prime}$ prefix, others have preserved it, while others have kept both forms. In the US there are many variant forms of common surnames found in Eire but where the variant forms are unknown. The US Irish surnames are thus not only more plentiful in numbers of types, they are more plentiful in the number of tokens for these types. This is not a unique situation as probably the same could be said for UK surnames.

Irish surnames follow the same characteristics as those in Canada, UK, and US. The relationship between count and rank is not a simple power curve which is complicated by typographical errors in the data sets. 


\section{A Gaelic Footnote}

The ED contains many Gaelic surnames such as: Ban Ui Parthalaim, Be Mhicgearailt, Bn Mhic Eoinin, Bn Nic Fhionngaile, Bn Ui Dhochartaigh, De Bhaldraithe, MacSiordachain, Mac An Bhrithimh, Mac Giolla Bhride, Mag Shamhrain, McMurchaidh, Mi Cheilleachair, Mic An Gheimhridh, Ne Rathaille, Ni Alastairbhaoill, Nic Toirdhbheallaigh, Nic An Tseachlainn, Nic Giolla Fhionnain, No Bhroin, O'H Eachtigheirn, O'Hallmhurain, O'Leanglaoich, O'Mhaoldhomhnaigh, Og O'Maonaigh, Ua Cathassaigh, Ue Chonchubair, Ui'chionnfaolaidh, Ui Bheaglaoich, and Uibh Eachach.

Apparently, it is becoming increasingly fashionable in Eire to render your surname in the Gaelic form. However, I am reliably informed that there are typographical errors in the above surnames. I wouldn't know, but I would not be surprised, and I suspect that there are many others like me. What we need is a depository of correctly spelled surnames (and forenames) - a register - used in our society, just as we have for the other words in our language.

\section{References}

Hanks, Patrick Wyndham. 2003. "Dictionary of American Family Names." 3 vols Oxford University Press: New York.

MacLyaght, Edward. 1985. Sixth Edition. "The Surnames of Ireland." Irish Academic Press: Dublin

Tucker, David Kenneth. 2001. "Distribution of Forenames, Surnames, and Forename-Surname Pairs in the United States." Names 49:69-96

2002. "Distribution of Forenames, Surnames, and Forename-Surname Pairs in Canada." Names 50:105132

2004. "The Forenames and Surnames from the GB Electoral Roll Compared with those from the UK 1881 Census." Nomina 27 